\title{
Modelling the diffusion of pottery technologies across Afro-Eurasia: emerging insights and future research
}

\author{
Peter Jordan ${ }^{1, *}$, Kevin Gibbs ${ }^{2}$, Peter Hommel ${ }^{3}$, Henny Piezonka ${ }^{4}$, \\ Fabio Silva ${ }^{5} \&$ James Steele ${ }^{5,6}$
}

Where did pottery first appear in the Old World? Statistical modelling of radiocarbon dates suggests that ceramic vessel technology had independent origins in two different hunter-gatherer societies. Regression models were used to estimate average rates of spread and geographic dispersal of the new technology. The models confirm independent origins in East Asia (c. 16000 cal BP) and North Africa (c. 12000 cal BP). The North African tradition may have later influenced the emergence of Near Eastern pottery, which then flowed west into Mediterranean Europe as part of a Western Neolithic, closely associated with the uptake of farming.

Keywords: Neolithic transition, hunter-gatherers, agriculture, pottery, statistical model, radiocarbon dating, diffusion

\section{Introduction}

The origins of pottery and farming - and their roles in the European Neolithic-have occupied a central place in archaeological debate for over a century. Long assumed to be derived from a single origin in the Near East, these innovations now appear to have more complex and largely independent histories, extending beyond Europe and the Near East. There is now abundant evidence that in two areas, North Africa and East Asia, pottery was made by hunter-gatherer groups earlier than $10000 \mathrm{cal} \mathrm{BP}$. Modelling of available radiocarbon dates from across Africa and Eurasia indicates that pottery sites get younger with distance from each of these two potential source regions, and suggests that the earliest European pottery traditions may ultimately find their origins in one or both of these centres.

In this article, we focus on the emergence of pottery in the Old World and model its dispersal at continental scales using a dataset of radiocarbon dates from early pottery sites in

\footnotetext{
Arctic Centre, University of Groningen, PO Box 716, 9700 AS Groningen, the Netherlands

Department of Anthropology, University of Nevada, Las Vegas, Box 455003, 4505 S. Maryland Parkway, Las Vegas, NV 89154, USA

3 Institute of Archaeology, University of Oxford, 36 Beaumont Street, Oxford OX1 2PG, UK

4 Eurasia Department, Deutsches Archäologisches Institut, Im Dol 2-6, Berlin 14195, Germany

5 Institute of Archaeology, University College London, 31-34 Gordon Square, London WC1H OPY, UK

6 School of Geography, Archaeology and Environmental Sciences, University of the Witwatersrand, Jan Smuts Avenue, Braamfontein, Johannesberg 2000, South Africa

* Author for correspondence (Email: p.d.jordan@rug.nl)
} 
Africa and Eurasia. This enables us to consider several related questions: where are the main centres of early pottery innovation? What was the pace, direction and timing of pottery dispersals out of these centres into adjacent regions? How, and via what routes, was the first pottery introduced into Europe? What role did pre-agricultural populations play in these early pottery origins and dispersals?

Among archaeologists in Western Europe, pottery has commonly been regarded as the definitive artefact of the prehistoric farmer (Barker 2006: 74), and its dispersal from the Near East into Europe as an integral feature of the Neolithic. It is probable that pottery did spread with farming from the Near East into some regions of Europe, making this 'consensus' story true, at least in part. The concept of a combined dispersal of pottery and farming is therefore central to what might be termed the 'Western' variant of the Neolithic. Archaeologists working in other parts of Eurasia have, however, identified a different sequence of developments. Across much of the eastern Baltic, Eastern Europe, Russia, Siberia and beyond, it was the independent emergence of pottery among hunting and gathering societies that became the definitive feature of an alternative 'Eastern' Neolithic not associated with agriculture.

If two different kinds of Neolithic were gathering pace across Holocene Eurasia, how, then, did these developments play out over time and space, and what was the relationship between them? In recent years, archaeologists have started to examine whether there were several different routes for the arrival of early pottery into Europe. For example, Davison et al. (2009) used mathematical modelling to examine possible contributions to European Neolithic pottery traditions. They confirmed the 'consensus' story of the Western Neolithic, with farming spreading with pottery from the Near East, but also identified a second Eastern Neolithic dispersal. This involved pottery uptake among hunter-gatherers, with the origins of these ceramic traditions probably located on the eastern margins of Europe, in the forest steppe of the southern Urals. Over the last ten years, a broader appreciation of this Eastern Neolithic has been growing. For example, a number of scholars now accept the possibility of an eastern origin for the pointed-base Ertebølle tradition (Hallgren 2004; Gronenborn 2009: 529; Piezonka 2015).

The relationship between the earliest East Asian pottery traditions and those apparently spreading into Eastern Europe from the forest-steppe zone of the southern Urals has also seen much rather speculative debate (Jordan \& Zvelebil 2009). Many dates and details pertaining to the earliest pottery traditions of inner Eurasia remain uncertain, although some have attempted to link early pottery traditions across eastern and western Siberia (Kuzmin \& Vetrov 2007). In a preliminary attempt at a pan-Eurasian synthesis of available dates and materials based on data collected by Hommel (2009), Jordan and Zvelebil (2009: 68-72) generated a descriptive time-space mapping of early pottery radiocarbon dates from across Eurasia that appeared to lend preliminary support to a general east-west trend across Eurasia (Figure 1).

They attempted to situate these developments within an even larger Afro-Eurasian context, suggesting that the pottery that emerged in the Near East may not have been the result of an independent local innovation. Instead, Neolithic pottery in the Near East may have been influenced by the early pottery traditions of North Africa (see Gronenborn 2009: 532). As in East Asia, the earliest pottery in North Africa was made by hunter-gatherers. 
Early Holocene pottery sites are found within a $4000 \mathrm{~km}$-long band encompassing the southern Sahara and northern Sahel, with early dates clustering in the Middle Nile valley and the Western Desert of Egypt, in the vicinity of the mountainous regions of southern Algeria and northern Niger, and at Ounjougou, Mali (Close 1995; Nelson et al. 2002; Jesse 2003; Huysecom et al. 2009). Although the presence of early dates for pottery production in Africa is now widely acknowledged, there has been little investigation of possible North African influence on the development of early pottery traditions in the Near East.

In their preliminary model of pottery dispersals across Afro-Eurasia, Jordan and Zvelebil (2009: 70-72) described:

1) the initial origin(s) of pottery among hunter-gatherer societies of the late Pleistocene of East Asia;

2) a gradual westward dispersal across the forest-steppe regions of southern Siberia, into the southern Urals, and along the northern shores of the Caspian Sea, during the early Holocene, from where it spread into the margins of Eastern Europe;

3) a northerly dispersal via the Upper Volga River, through central European Russia, into Karelia, the eastern Baltic and northern Scandinavia, which formed various local traditions of pointed-based comb-pitted wares;

4) more tentatively, a further spread of pottery via Central Asia, southwards along the eastern shore of the Caspian Sea into the farming communities of north-western Iran and northern Syria, where pottery may have merged with existing ceramic traditions, perhaps ultimately derived from North Africa; and finally

5) a model for the traditional combined 'agricultural Neolithic' dispersal of pottery into south-eastern Europe from the Near East.

In this paper, we build on these preliminary attempts at general synthesis by analysing an expanded set of radiocarbon dates for Eurasia and Africa in order to test key aspects of the model, including:

1) the timing and pace of the diffusion of pottery-making traditions out of the main centres of early pottery innovation into adjacent regions;

2) the boundary along which East Asian and African early pottery diffusion fronts eventually converged; and

3) the influences of East Asian and of African (potentially via the Near East) hunter-gatherer pottery traditions on the appearance of the first pottery in Europe.

\section{Database and modelling approach}

The database consists of radiocarbon dates from 942 archaeological sites associated with the earliest pottery technologies in Afro-Eurasia (see online supplementary material). Information about the dates was gleaned from site reports, academic publications, radiocarbon laboratory lists and existing databases both in print and online. Calibration of the raw radiocarbon data was performed using $\mathrm{OxCal} 4.1$ and the IntCal09 calibration curve (Bronk Ramsey 2009; Reimer et al. 2009). Contextual data from the reports was examined to ensure that all dates had clear associations with early pottery.

(C) Antiquity Publications Ltd, 2016 
Our analysis aimed to discern diffusion gradients that might indicate how the new technology spread from its origins. Firstly, we screened the database to select

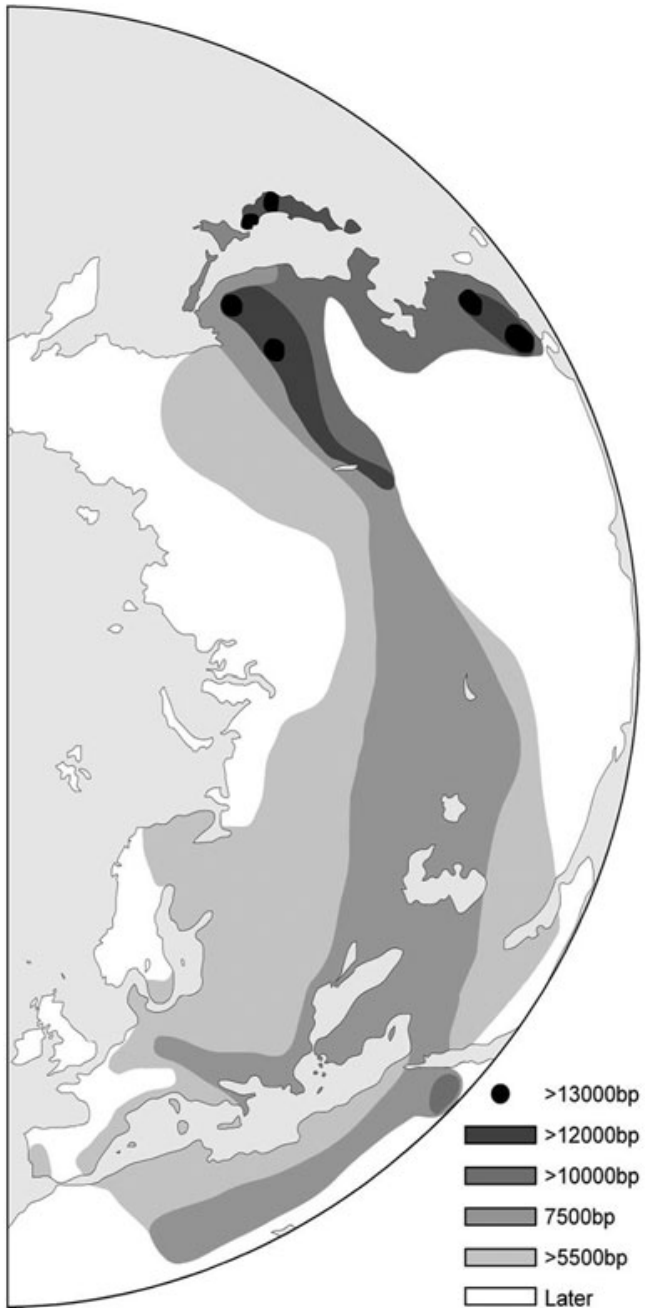

Figure 1. Our first attempt at a periodisation of the spread of early pottery in northern Eurasia (from Jordan \& Zvelebil 2009: fig. 1.5) single dates (or averages of multiple dates, where appropriate) for all of the sites that could be used in the analysis. The dataset was filtered to select the oldest site in a given neighbourhood following the moving-window methodology elaborated in Russell et al. (2014). This improved the accuracy of the regression estimation by reducing the noise provided by sites that do not correspond to first arrivals of pottery in the neighbourhood. Defining the neighbourhood radius as $100 \mathrm{~km}$, and retaining only the oldest site within any such neighbourhood, reduced our initial sample to 396 dated sites. Figure 2 represents the sites selected using this method (bottom), as well as all sites in the dataset (top), including information on associated subsistence strategies. A contoured isochron map of observed pottery arrival times was then generated in GRASS (GRASS Development Team 2012) using bicubic interpolation with Tykhonov regularisation (the routine was r.resamp.bspline, with $\lambda=0.01$ ).

The statistical methodology used to infer trends in the earliest pottery dates involved fitting regression models (reduced major axis; Steele 2010; Silva \& Steele 2014) to sets of paired dates (mean calibrated radiocarbon ages) and distances from a possible origin. This enabled us to estimate the mean rate of spread of the new technology (using the regression slope coefficient), and the proportion of the variation in arrival times that was accounted for by that trend (using the correlation coefficient). Distances were estimated on a projected digital map using cumulative cost-distance and least-cost path mapping techniques. By these means we measured distances across a homogeneous surface (subject only to a rule that paths could not cross large bodies of water); we also measured distances across a heterogeneous surface, where diffusion corridors were coded to afford less resistance to movement (see below). As it was not known a priori which centre of innovation was ancestral to the pottery found at locations that are very distant from either source, we estimated speeds of spread using only 
Peter Jordan et al.

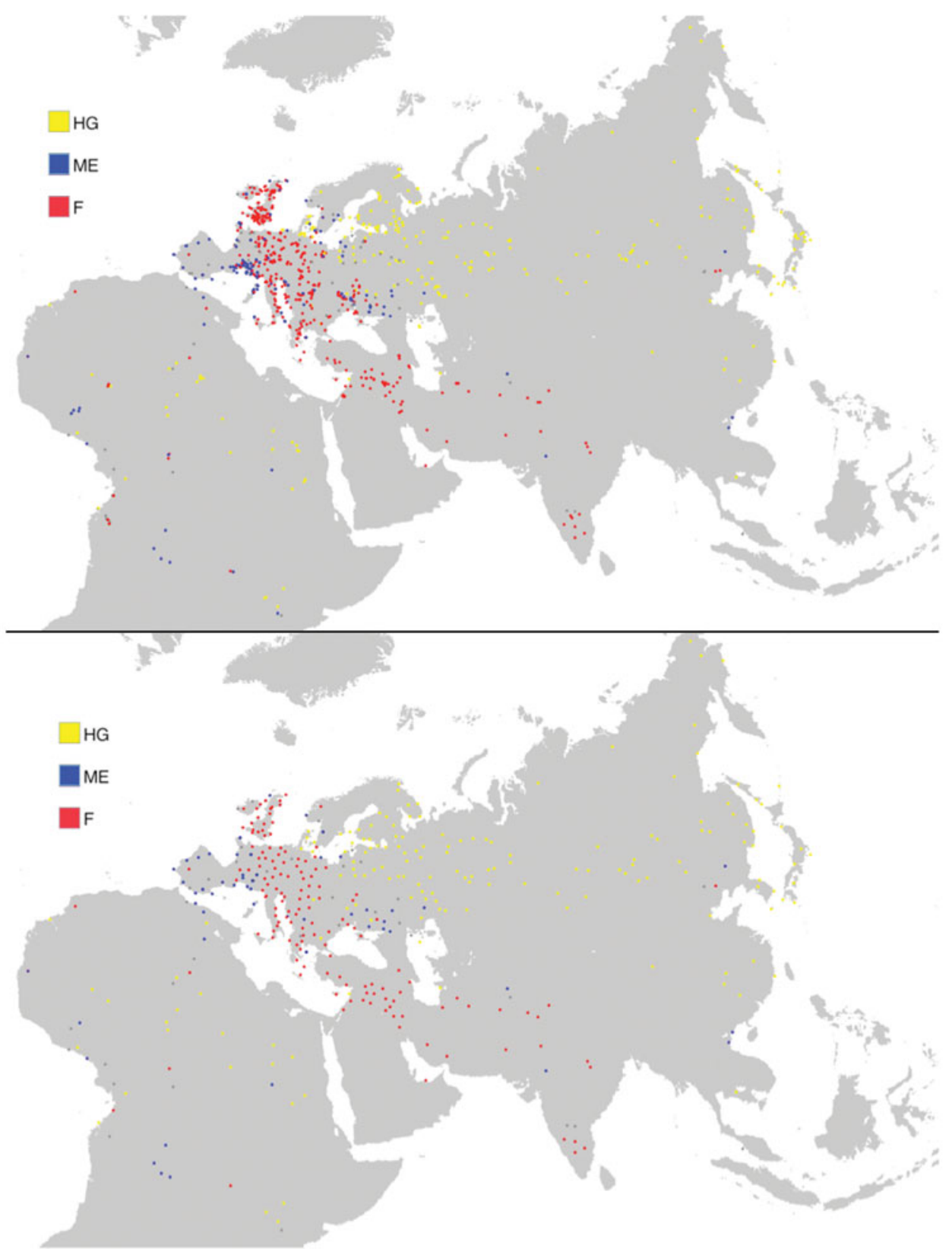

Figure 2. Plot of all 942 sites with pottery in the database (top) and the 396 retained for analysis (bottom), coloured with respect to associated subsistence economy (HG = hunting and gathering; $M E=$ mixed economy; $F=$ farming; grey $=$ unknown or uncertain).

(C) Antiquity Publications Ltd, 2016 
sites located no greater than a specified cut-off distance from each source location. Finally, having estimated the average speeds of subsequent diffusion, we also modelled the boundary between the two spread zones as they converged. Further details of our methods are given in the online supplementary material (see also Silva \& Steele 2014).

\section{Centres of innovation}

For the present study, we assumed just two independent centres of innovation, one in China and one in Africa. It is possible that there were multiple independent centres of innovation in East Asia, but it remains the case that the earliest dates for pottery are from China (Wu et al. 2012); a diffusion of knowledge of the technology to Japan and to the Russian Far East by mobile hunter-gatherers therefore seems to us to be the most parsimonious starting hypothesis. Similarly, while it is also possible that pottery technology was an independent invention in the Near East, we have assumed that the older dates for pottery in North Africa are consistent with its subsequent diffusion into western Eurasia from there. A number of locations in North Africa have sites with pottery dated to the early Holocene. Ounjougou, in Mali, has some of the very earliest dates but lies quite distant from the Near East (Huysecom et al. 2009). Pottery that is potentially as early as the Ounjougou material has been found at sites that are geographically closer to the Near East. Bir Kiseiba, in the Western Desert of Egypt, has the earliest dates coming from site E-79-8, although with large margins of error, and in the central Nile Valley of Sudan, the Saggai site has produced the region's earliest date for pottery (Close 1995).

Our modelling techniques also require a point location for the source of the innovation. In reality, of course, it would be more realistic to assign the origin of the technique to a broader region (of which the excavated archaeological record gives us only a glimpse). We have taken Xianrendong Cave in China (e.g. Wu et al. 2012) as the origin point in East Asia, and Saggai in Sudan (e.g. Caneva 1983) as the origin point in Africa. The exact location of the source point in the broader region of origination is unlikely to significantly affect the modelled results. These sites have some of the earliest dates proposed for pottery in their respective regions. Since their age estimates may also be error-prone (see Discussion, below), we do not force the regression model to use them as the origination (regression intercept) ages, seeking instead only to estimate the mean gradient in ages of first archaeologically observed occurrences of pottery, with distance. The radiocarbon dates at the source points therefore only have influences on the outcome of the modelling that are qualitatively similar to those of any other site in the database. Thus, we expect our results to be robust to variation in the exact location of the source of the innovation within a region, and to factor in any single early site's estimated radiocarbon age.

\section{Prehistoric corridors}

The present-potential distribution of major modern biomes (Olson et al. 2001) has been used as a first degree of approximation to the distribution of prehistoric biogeographic corridors, or zones of accelerated spread. We identified a priori two possible favourable biomes. The first, 'Mediterranean forest/woodland/scrub', is a biome favouring rapid diffusion of potterymaking in the circum-Mediterranean zone, and is assigned as a possible 'boost' habitat for 
pottery traditions associated in our models with the African centre of innovation. This biome is identified as containing sites with early-arriving pottery in our initial exploratory analysis (Silva et al. 2014). The second biome is 'temperate broadleaf/mixed forest' and 'temperate grassland/savannah/shrubland' (a biome mainly represented in Eurasia by the Central Asian steppe), a potentially favourable habitat for the accelerated diffusion of pottery originating in the East Asian centre of innovation (see Figure S2 in the supplementary material). A 'boost factor' was associated with each of these two corridors, corresponding to the extent to which movement is accelerated across that part of the map. The two boost factors are free parameters that were optimised in order for the model to best-fit the empirical data (see supplementary material for more details).

\section{Results}

\section{Isochron maps}

Figure 3a shows the interpolated isochron map of first-observed pottery dates in the regions under study, and Figure $3 \mathrm{~b}$ shows this as a time series of the areas lying within individual isochrons at 1000- and 500-year intervals. It is evident from Figure 3b that by $14000 \mathrm{cal}$ BP there were four pottery-using zones in East Asia, with a gap between them due to an absence of early dated sites. The oldest Chinese sites seem to be earlier than those in Japan and the Russian Far East. As is visible in Figure 3a, if the Japanese and East Siberian sites derive their pottery from China, it is noteworthy that, as yet, we do not have sites dated before $11000 \mathrm{cal}$ BP from the intervening region (north-eastern China, Korea). By $10000 \mathrm{cal} \mathrm{BP}$, it seems that the mainland East Asian pottery-using zones have coalesced, while pottery use is also recorded in the eastern Urals. Doubts about the validity of these early dates have been raised, however (e.g. Usacheva 2001), and there are no chronologically intermediate finds to link it directly with East Asian complexes. Meanwhile, the first pottery is also evident in North Africa.

By $8000 \mathrm{cal}$ BP, pottery is found throughout the Fertile Crescent. Pottery is also spreading into Europe with the onset of the 'agricultural Neolithic' transition. By $7500 \mathrm{cal}$ BP, the Asian and African spread zones have coalesced in the Middle East. Pottery is spreading around the Black Sea from the south-east (the Fertile Crescent), and around the Caspian Sea. Meanwhile, the European Neolithic transition is spreading northwards. In another 500 years, by $7000 \mathrm{cal}$ BP, most of the map is filled.

\section{The diffusion of pottery-making: geographic factors}

With no boost along our hypothesised corridors, an 'almost geography-free' baseline model partitions the map into two diffusion zones with pottery-making diffusing from China at a mean speed of $0.3 \mathrm{~km} / \mathrm{yr}$ and from Africa at a mean speed of $0.8 \mathrm{~km} / \mathrm{yr}$ (Table 1 ). That model, however, is not a good fit: in each of the putative Asian and African diffusion zones, those rates of spread account for only about 10 per cent of the variance in radiocarbon dates (from $r^{2}$ values, using the values for $r$ in Table 1). As we hypothesised, allowing for boost along geographic corridors and through favourable habitats increased the fit of the model three-fold, with the best-fitting solutions yielding values for Pearson's $r$

(C) Antiquity Publications Ltd, 2016 
a
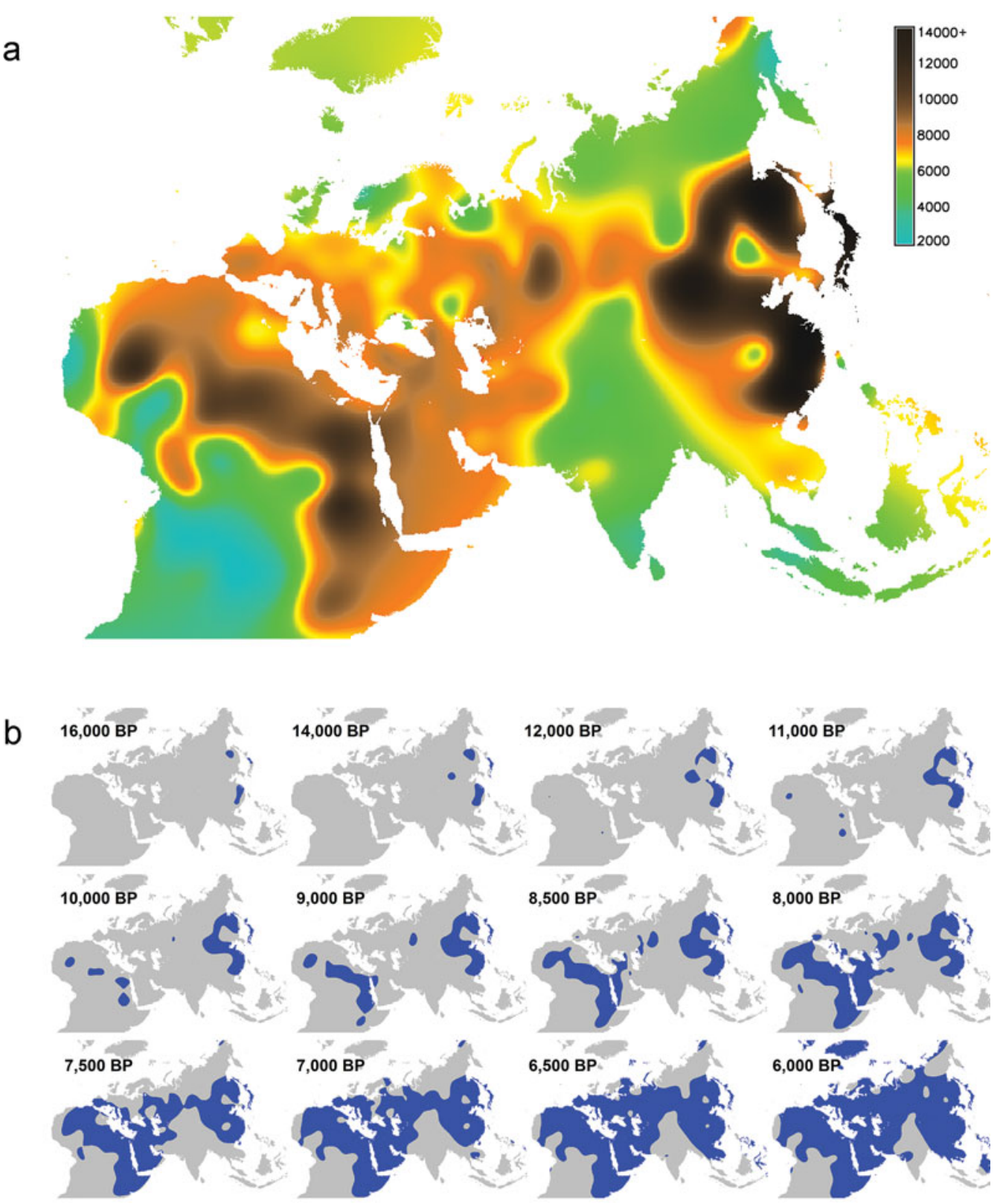

Figure 3. a) Interpolated isochron surface fitted to the subset of sites retained for analysis, with a landlsea mask subsequently superimposed; b) the isochron surface (Figure 3a), with threshold values identifying the boundary contour at 1000 cal years $B P$ intervals and (for the later part) at 500 cal years BP intervals. 
Table 1. Rates of spread ('speeds') and goodness-of-fit statistics for two models: one with no boosts $(1 \times 1)$ and another with a five-fold boost along the Eurasian corridor, and a seven-fold boost along the circum-Mediterranean corridor-a best-fitting solution. See Table S1 in online supplementary material for details on all best-fitting solutions.

\begin{tabular}{|c|c|c|c|c|c|c|c|c|}
\hline \multirow[b]{2}{*}{$\begin{array}{l}\text { Boost factors } \\
(\text { Asia } \times \text { Africa })\end{array}$} & \multicolumn{2}{|c|}{ Asia } & \multicolumn{6}{|c|}{ Africa } \\
\hline & $\begin{array}{c}\text { Pearson } \\
r\end{array}$ & $\begin{array}{c}\text { Spearman } \\
\text { rho }\end{array}$ & $\begin{array}{l}\text { Speed } \\
\text { corridor }\end{array}$ & $\begin{array}{c}\text { Speed } \\
\text { elsewhere }\end{array}$ & $\begin{array}{c}\text { Pearson } \\
r\end{array}$ & $\begin{array}{c}\text { Spearman } \\
\text { rho }\end{array}$ & $\begin{array}{l}\text { Speed } \\
\text { corridor }\end{array}$ & $\begin{array}{c}\text { Speed } \\
\text { elsewhere }\end{array}$ \\
\hline $1 \times 1$ & -0.33 & -0.37 & 0.31 & 0.31 & -0.31 & -0.44 & 0.79 & 0.79 \\
\hline $5 \times 7$ & -0.57 & -0.58 & 1.25 & 0.25 & -0.51 & -0.63 & 3.23 & 0.46 \\
\hline $\begin{array}{l}\text { Average speeds of } \\
\text { all best-fitting } \\
\text { solutions }\end{array}$ & & & $1.20 \pm 0.07$ & $0.22 \pm 0.09$ & & & $3.32 \pm 1.45$ & $0.45 \pm 0.09$ \\
\hline
\end{tabular}

as high as 0.6 (maximum $r^{2}=0.36$ ). We explored the parameter space of our costdistance model, allowing variable boost factors along what are, in effect, an Asian east-west, present-potential, steppe-forest corridor, and a circum-Mediterranean corridor composed principally of present-potential Mediterranean forest, woodland and scrub (see online supplementary material). In these optimised, biome-dependent diffusion models, the front speeds through favourable and 'baseline' habitat support a six- or seven-fold acceleration in the favoured biomes. The mean front speed in the Asian-origin diffusion zone is $1.2 \mathrm{~km} / \mathrm{yr}$ in favoured habitat (steppe, temperate forest) against $0.2 \mathrm{~km} / \mathrm{yr}$ elsewhere, and the mean front speed in the African-origin diffusion zone is $3.3 \mathrm{~km} / \mathrm{yr}$ in the favoured habitat (Mediterranean forest/woodland/scrub), against $0.5 \mathrm{~km} / \mathrm{yr}$ elsewhere (Table 1 ).

\section{The boundary between the two diffusion zones}

Figure 4 shows the predicted isochrons for the average age of the first archaeologically observed pottery use for a model with a boost factor of five for the Asian corridor and seven for the African one, chosen from the set of best-fitting solutions. It shows the modelled boundary between the pottery-diffusion zones for the Asian and African innovation centres. Although other best-fit solutions are possible, differing in where this boundary is drawn east of the Caspian and into South Asia, all display a boundary essentially as shown here (see Figure S6 in the supplementary material). It crosses northern Europe and the Caucasus and divides the European data into one zone (south of the boundary), where early pottery is associated with farming, and a second (north of the boundary) where it is associated with hunter-gatherers. These zones would correspond to the African and Asian potterydiffusion zones respectively. This boundary in Northern and Eastern Europe, which does not correspond to the biome boundary between present-potential temperate broadleaf/mixed forest or steppe and the Mediterranean forest/woodland/scrub biomes (see supplementary material), appears to be a robust result, and was also found in our earlier exploratory study (Silva et al. 2014). This finding is, therefore, our most significant scientific result. Our (C) Antiquity Publications Ltd, 2016 


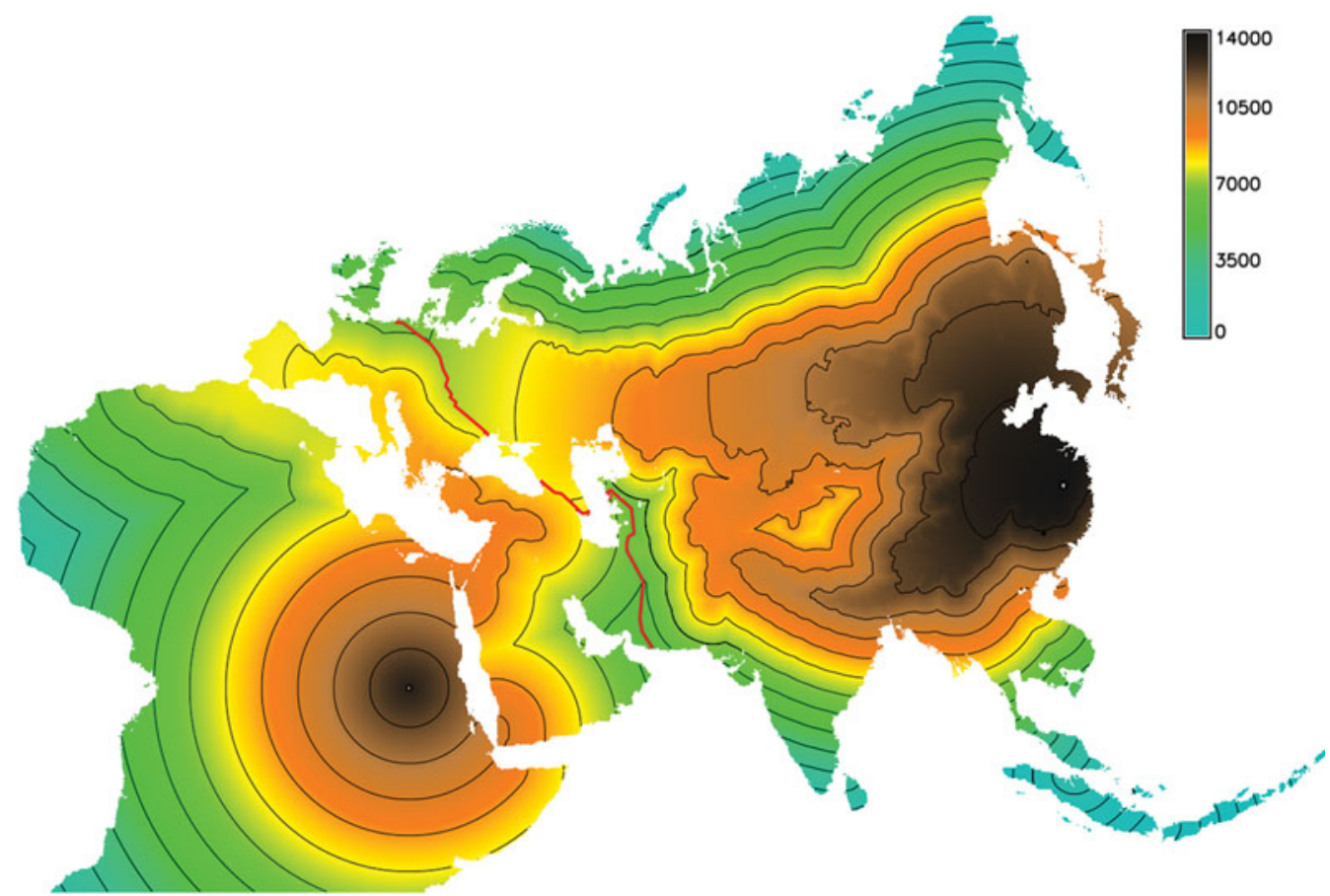

Figure 4. Modelled first arrival times for the spread of pottery from the two considered centres of innovation, with 1000-year interval contour for a typical best-fitting model (the $5 \times 7$ model).

modelling methodology takes no account of the economic category into which each site and date was assigned; the coincidence of this partitioning of the dataset between farmer and hunter-gatherer pottery users in Europe, as shown by the coloured symbols of Figure 5, is independent corroboration of the coherence of our analysis.

\section{Discussion}

Our regression models have estimated average rates of spread of pottery technology. These yield an archaeologically plausible Eurasian frontier along which East Asia-derived traditions of hunter-gatherer pottery eventually converged with traditions associated with early agriculture in Europe but possibly originating in the Early Holocene traditions of North Africa.

Further work in the area stretching east of the Urals into western Siberia would help to confirm or refute the hypothesis of an East Asian origin for pottery use by prehistoric boreal hunter-gatherers farther east. Our hypothesis of a northern African origin for Near Eastern pottery traditions is also controversial. We recognise that some of the age estimates for North African pottery from the pre-AMS era are probably wrong. Recently reported ${ }^{14} \mathrm{C}$ dates for early pottery in Mali are, however, consistent with other contextually secure dates for early pottery in the Central Saharan mountains, and in the Eastern Sahara and the Nile Valley. These dates consistently suggest the use of pottery in the warm and

(C) Antiquity Publications Ltd, 2016 


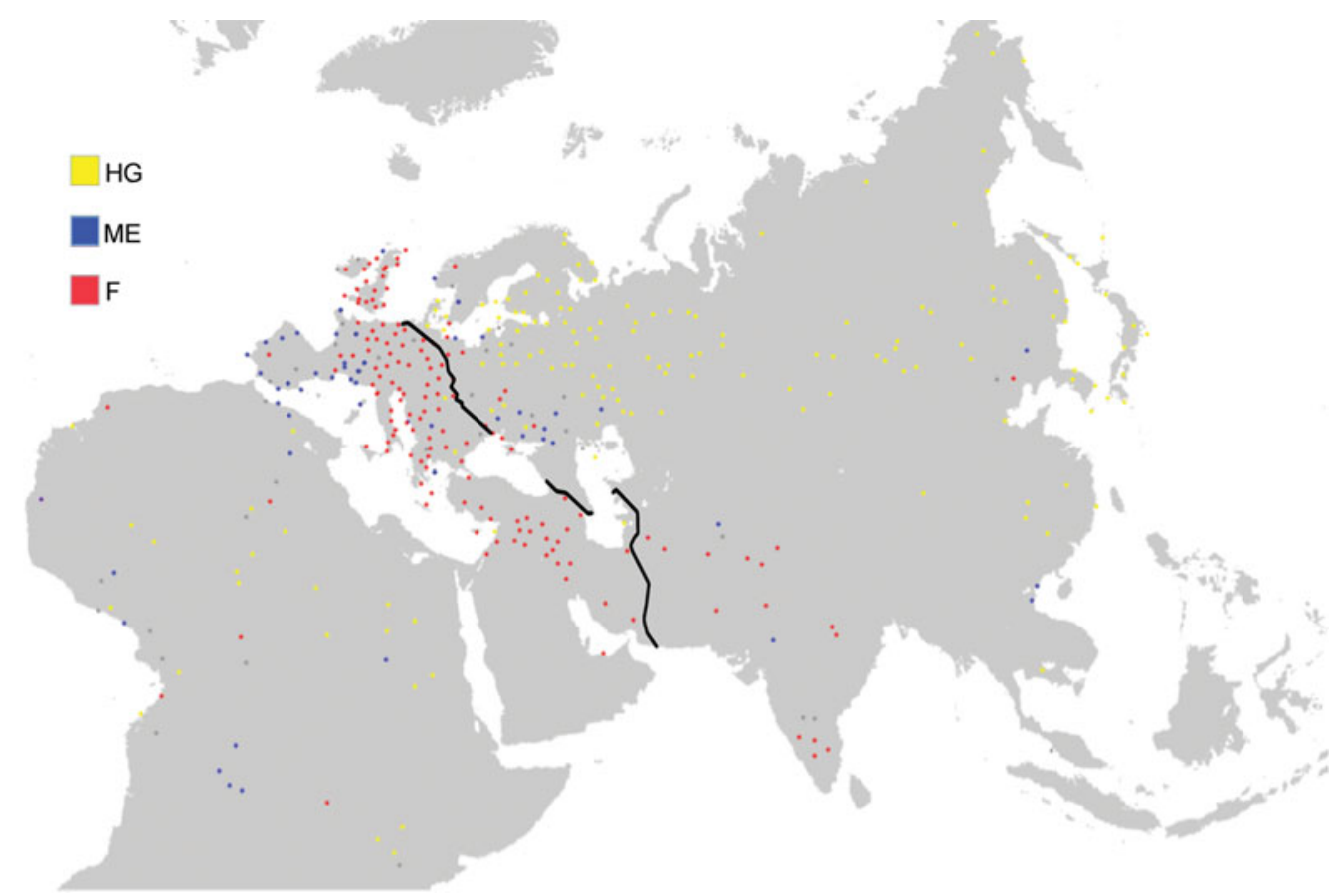

Figure 5. Typical boundary between the diffusion zones for Asian and African pottery for a model with a boost factor of five for the Asian corridor and seven for the African one. Other best-fit solutions differ in where this boundary is drawn east of the Caspian and into South Asia (see online supplementary material), but all display a boundary crossing Northern Europe and the Caucasus, and dividing the European data into a zone (south of that boundary) associated with farming and a zone (north of the boundary) associated with hunter-gatherers. This would correspond to the African and Asian pottery diffusion zones respectively. (HG = hunting and gathering; $M E=$ mixed economy; $F=$ farming; grey= unknown or uncertain.)

wet early Holocene climatic phase in the Sahara and Sahel, during the period 11000 $10000 \mathrm{cal}$ BP (Huysecom et al. 2009). Nevertheless, the hypothesis of a diffusion out of Africa as the source of pottery technology in the Neolithic of the Near East requires much more testing. This must involve a more refined understanding of the chronology of early pottery-making at different locations in the Fertile Crescent, but also further analysis of the details of the techniques used, stylistic traditions and context of use, which might be evidence for or against such large-scale continuity in chains of cultural transmission. In general, further assessment of the reliability of all dates used in the analysis ('chronometric hygiene'; Kuzmin 2006; Graf 2009) would strengthen our interpretations and benefit future studies.

Our models predicted a boundary between the Asian-derived hunter-gatherer pottery zone, and the Africa/circum-Mediterranean-derived farmer pottery zone, that coincides (serendipitously) with the distribution of those economic types in our database of potterybearing sites from Europe. This suggests that diffusion of the innovation was linked, in each case, to other cultural and economic factors that made it a useful technology to adopt. We have not considered here the functional aspects of early pottery use, but these must surely (C) Antiquity Publications Ltd, 2016 
be a central element of future debates about the diffusion of this innovation. It is clear that pottery vessels found diverse uses in food preparation and storage, and that this functional variation must relate in some way to the distinctive ecology and subsistence traditions of each pottery-using society. Residue analysis of Incipient Jōmon pottery vessels in Japan suggests that they were being used to process aquatic foods, implying a subsistence focus on freshwater and marine environments (Craig et al. 2013). In contrast, early pottery use in a green Sahara or Sahel has been associated with the boiling of newly abundant, wild cereal grains to make them more digestible (Huysecom et al. 2009). In prehistoric farming societies in Europe, meanwhile, residue analyses suggest a wide range of uses for pottery vessels, including the storage and processing of dairy products (e.g. Evershed et al. 2008). Food storage and preparation traditions were probably major influences on the continuity of cultural transmission of associated technologies such as pottery (e.g. Fuller \& Rowlands 2011), and it would be useful to incorporate these into future modelling work.

Our analyses have focused on estimating rates of innovation diffusion, and on predicting the average radiocarbon ages at which pottery becomes locally visible to archaeological detection; but it is also relevant to consider the possible mechanisms of diffusion. In the literature on the demography of the Neolithic transition, this is typically posed as a dichotomy: either farming was transmitted within biological lineages that expanded in space as their numbers grew, or it was transmitted to hunter-gatherers by a process of imitation. The spread of hunter-gatherer pottery technology out of East Asia suggests this to be a false dichotomy. Mobility between bands by marriage transfers, and local mixing by periodic aggregation and splitting, are well attested as the main mechanisms of information transfer in the ethnographic record of hunter-gatherer peoples. It seems plausible that a constant background flux of movement between groups by people who had already acquired the skills to make and use pottery was the vector of transmission for prehistoric hunter-gatherer pottery technology too. The rapidity with which the technique was adopted once introduced would then have depended on its perceived benefits in relation to the costs of learning and of subsequent production. It is theoretically possible, of course, that the technology spread within Eurasia through the spatial expansion of a single population, but in the absence of confirmatory evidence, the assumption must be against such a drastic replacement scenario.

\section{Acknowledgements}

The idea for this paper emerged from an earlier project entitled 'Use of Ceramics by Old World HunterGatherers', which was co-directed by Peter Jordan and Marek Zvelebil, and hosted by the UK Arts \& Humanities Research Council (AHRC) Centre for the Evolution of Cultural Diversity (2006-2010) (see: http://www.cecd.ucl.ac.uk/home/). Peter Hommel also expanded the initial early pottery dataset for the present study. Final work on this paper was completed as part of the project 'Ceramics before farming: prehistoric pottery dispersals in Northeast Asia', funded by the UK Leverhulme Trust (2011-2014) (grant reference: F/00 152/AM) (PI: Peter Jordan; Research Fellow: Kevin Gibbs). Spatial modelling of the dataset was supported by an AHRC grant to the Centre for the Evolution of Cultural Diversity, UCL, and was carried out by Fabio Silva and James Steele in consultation with the project leaders. We would like to acknowledge the benevolent influence of the late Pavel Dolukhanov in the earlier development of this field of application for archaeological diffusion models. We are also grateful to Yaroslav V. Kuzmin (Institute of Geology \& Mineralogy, Siberian Branch of the Russian Academy of Sciences, Novosibirsk, Russia) for alerting us to additional radiocarbon dates and for general discussions pertaining to the chronology of early pottery traditions in Eurasia. 


\section{Supplementary material}

To view supplementary material for this article, please visit http://dx.doi.org/10.15184/ aqy. 2016.68

\section{References}

BARKER, G. 2006. The agricultural revolution in prehistory: why did foragers become farmers? Oxford: Oxford University Press.

BRONK RAMSEY, C. 2009. Bayesian analysis of radiocarbon dates. Radiocarbon 51: 337-60.

Caneva, I. (ed.). 1983. Pottery-using gatherers and hunters at Saggai (Sudan): preconditions for food production. Rome: Origini XII.

Close, A.E. 1995. Few and far between: early ceramics in North Africa, in W.K. Barnett \& J.W. Hoopes (ed.) The emergence of pottery: technology and innovation in ancient societies: 23-37. Washington, D.C.: Smithsonian Institution Press.

Craig, O.E., H. Saul, A. LuCQuin, Y. Nishida, K. Taché, L. Clarke, A. Thompson, D.T. Altoft, J. Uchiyama, M. Ajimoto, K. Gibbs, S. ISAKSSON, C.P. HERON \& P. JordAN. 2013. Earliest evidence for the use of pottery. Nature 496 : 351-54. http://dx.doi.org/10.1038/nature12109

Davison, K., P.M. DolukHanov, G.R. SARSON, A. Shukurov \& G.I. Zaitseva. 2009. Multiple sources of the European Neolithic: mathematical modelling constrained by radiocarbon dates. Quaternary International 203: 10-18. http://dx.doi.org/10.1016/j.quaint.2008.04.013

Evershed, R.P., S. Payne, A.G. Sherratt, M.S. Copley, J. Coolidge, D. Urem-Kotsu, K. KoTSAKIS, M. ÖZDOĞAN, A.E. ÖZDOĞAN, O. NieuWENHUYSE, P.M.M.G. AKKermans, D. BAIley, R.-R. AndeEscu, S. CAMPBell, S. Farid, I. Hodder, N. Yalman, M. Özbaşaran, E. BiÇAKCI, Y. GARFINKEL, T. LEVY \& M.M. BurTON. 2008. Earliest date for milk use in the Near East and southeastern Europe linked to cattle herding. Nature 455: 528-31. http://dx.doi.org/10.1038/nature07180

FulLER, D.Q \& M. Rowlands. 2011. Ingestion and food technologies: maintaining differences over the long-term in West, South and East Asia, in T. Wilkinson, S. Sherratt \& J. Bennet (ed.) Interweaving worlds: systematic interactions in Eurasia, $7^{\text {th }}$ to $1^{\text {st }}$ millennia BC: 36-60. Oxford: Oxbow.

GraF, K.E. 2009. 'The good, the bad, and the ugly': evaluating the radiocarbon chronology of the middle and late Upper Paleolithic in the Enisei River valley, south-central Siberia. Journal of Archaeological Science 36: 694-707. http://dx.doi.org/10.1016/j.jas.2008.10.014
GRASS Development Team. 2012. Geographic Resources Analysis Support System (GRASS) software. Available at: http://grass.osgeo.org (accessed 23 February 2016).

Gronenborn, D. 2009. Transregional culture contacts and the Neolithization process in northern Central Europe, in P. Jordan \& M. Zvelebil (ed.) Ceramics before farming: the dispersal of pottery among prehistoric Eurasian hunter-gatherers: 527-50. Walnut Creek (CA): Left Coast.

Hallgren, F. 2004. The introduction of ceramic technology around the Baltic Sea in the $6^{\text {th }}$ millennium, in H. Knutsson (ed.) Coast to coast-arrival: results and reflections: 123-42. Uppsala: Department of Archaeology and Ancient History, Uppsala University.

Hommel, P. 2009. Hunter-gatherer pottery: an emerging ${ }^{14} \mathrm{C}$ chronology, in P. Jordan $\&$ M. Zvelebil (ed.) Ceramics before farming: the dispersal of pottery among prehistoric Eurasian hunter-gatherers: 561-69. Walnut Creek (CA): Left Coast.

Huysecom, E., M. Rasse, L. Lespez, K. Neumann, A. Fahmy, A. Ballouche, S. Ozainne, M. Maggetti, Ch. Tribolo \& S. Soriano. 2009. The emergence of pottery in Africa during the tenth millennium cal BC: new evidence from Ounjougou (Mali). Antiquity 83: 905-17. http://dx.doi.org/10.1017/S0003598X00099245

JESSE, F. 2003. Early ceramics in the Sahara and the Nile Valley, in L. Krzyżaniak, K. Kroeper \& M. Kobusiewicz (ed.) Cultural markers in the later prehistory of northeastern Africa and recent research (Studies in African Archaeology 8): 35-50. Poznań: Poznań Archaeological Museum.

JORDAN, P. \& M. ZvELEBIL. 2009. Ex oriente lux: the prehistory of hunter-gatherer ceramic dispersals, in P. Jordan \& M. Zvelebil (ed.) Ceramics before farming: the dispersal of pottery among prehistoric Eurasian hunter-gatherers: 33-89. Walnut Creek (CA): Left Coast.

KuZMIn, Y.V. 2006. Chronology of the earliest pottery in East Asia: progress and pitfalls. Antiquity 80: 362-71. http://dx.doi.org/10.1017/S0003598X00093686

Kuzmin, Y.V. \& V.M. Vetrov. 2007. The earliest Neolithic complex in Siberia: the Ust'-Karenga 12 site and its significance for the Neolithisation process in Eurasia. Documenta Praehistorica 34: 9-20.

(C) Antiquity Publications Ltd, 2016 


\section{Modelling the diffusion of pottery technologies across Afro-Eurasia}

Nelson, K., M.C. Gatto, F. Jesse \& M.N. Zedeño. 2002. Holocene settlement of the Egyptian Sahara, volume 2: the pottery of Nabta Playa. New York \& London: Kluwer Academic/Plenum.

Olson, D.M., E. Dinerstein, E.D. Wikramanayake, N.D. Burgess, G.V. Powell, E.C. UnderWoOd \& K.R. KASSEM. 2001. Terrestrial ecoregions of the world: a new map of life on earth. BioScience 51: 933-38. http://dx.doi.org/10.1641/00063568(2001)051[0933:TEOTWA]2.0.CO;2

PiEZONKA, H. 2015. Jäger, Fischer, Töpfer. Wildbeutergruppen mit früher Keramik in Nordosteuropa im 6. und 5. Jahrtausend v. Chr. (Archäologie in Eurasien 30). Bonn: Habelt.

Reimer, P.J., M.G.L. Baillie, E. Bard, A. Bayliss, J.W. Beck, P.G. BlackWell, C. Bronk Ramsey, C.E. BuCK, G.S. Burr, R.L. EdWARdS, M. Friedrich, P.M. Grootes, T.P. GUILdERSON, I. Hajdas, T.J. Heaton, A.G. HogG, K.A. Hughen, K.F. Kaiser, B. Kromer, F.G. MCCORMAC, S.W. MANNING, R.W. REIMER, D.A. Richards, J.R. Southon, S. Talamo, C.S.M. Turney, J. VAn Der Plicht \& C.E. WeYhenMEYER. 2009. Intcal09 and Marine09 radiocarbon age calibration curves, $0-50,000$ years cal BP. Radiocarbon 51: 1111-50.

Russell, T., F. Silva \& J. STEELE. 2014. Modelling the spread of farming in the Bantu-speaking regions of Africa: an archaeology-based phylogeography. PLoS ONE 9(1): e87854.

http://dx.doi.org/10.1371/journal.pone.0087854
SiLVA, F. \& J. STEELE. 2014. New methods for reconstructing geographical effects on dispersal rates and routes from large-scale radiocarbon databases. Journal of Archaeological Science 52: 609-20. http://dx.doi.org/10.1016/j.jas.2014.04.021

Silva, F., J. Steele, K. Gibbs \& P. Jordan. 2014. Modeling spatial innovation diffusion from radiocarbon dates and regression residuals: the case of early Old World pottery. Radiocarbon 56: 723-32. http://dx.doi.org/10.2458/56.16937

STEELE, J. 2010. Radiocarbon dates as data: quantitative strategies for estimating colonization front speeds and event densities. Journal of Archaeological Science 37: 2017-30. http://dx.doi.org/10.1016/j.jas.2010.03.007

UsaCHeVA, I.V. 2001. Stratigraficheskie Pozitsii Neoliticheskikh Tipov Keramiki Poseleniya "VIII Punkt" na Andreevskoe Ozero I Nekotorye Obshchie Voprosy Neolita Zaural'ya, in V.R. Tsibul'skij, A.N. Bagashev \& E.I. Valeeva (ed.) Problemy Izucheniya Neolita Zapadnoj Sibiri: 116-33. Tyumen: Institute problem osvoeniya Severa SO RAN.

Wu, X., C. Zhang, P. Goldberg, D. Cohen, Y. Pan, T. ARPIN \& O. BAR-YoseF. 2012. Early pottery at 20,000 years ago in Xianrendong Cave, China. Science 336: 1696-700. http://dx.doi.org/10.1126/science.1218643

Received: 25 February 2015; Accepted: 22 May 2015; Revised: 21 October 2015 